\title{
Atomization Characteristics of Droplet and Morphologies of Arc Sprayed Ni-Al Particles and Composition Coatings
}

\author{
Jixiao Wang ${ }^{a, b, c} * \mathbb{D}$, Jun Wang ${ }^{a}$, Guo Jin ${ }^{a}, L_{i} W a n g^{b}$, Caisong Mo ${ }^{b}$, Li Ma ${ }^{b}$, Bairu Li ${ }^{b}$, Yongdong Wang ${ }^{c}$, \\ Hongxian Shen ${ }^{d}$, Xing Lu', Yunzhuo Lv', Siyu Yuan', Jian Zhangf, Yongjiang Huangd, Fuyang Cao ${ }^{d}$, Jianfei Sun ${ }^{d}$ \\ ${ }^{a}$ National University Science Park, Harbin Engineering University, 150001, Harbin, China \\ ${ }^{b}$ School of Mechanical and Electrical Engineering, Guangdong University of Petrochemical Technology, \\ 525000, Maoming, China \\ 'School of Materials Science and Engineering, Heilongjiang University of Science and Technology, \\ 150022, Harbin, China \\ ${ }^{d}$ School of Materials Science and Engineering, Harbin Institute of Technology, 150001, Harbin, China \\ eSchool of Materials Science and Engineering, Dalian Jiaotong University, 116028, Dalian, China \\ ${ }^{f}$ Anshan Iron and Steel Affiliated Enterprise Metallurgical Equipment Repair Technology Company, \\ 114021, Anshan, China
}

Received: January 17, 2019; Revised: March 17, 2019; Accepted: May 02, 2019

\begin{abstract}
Droplet atomization characteristics and its morphology in twin-wire arc sprayed (TWAS) Ni-Al were explored in depth. Both numerical model and theoretical method were built for calculating the process of the droplet deformation and breakup in air flow, which based on the standard $k-\varepsilon$ model and the volume of fluid (VOF) dual-phase flow model. The atomization characteristics of double droplets and three droplets were also studied in the atomization process by simulation. The micro structure and the morphology of the composite coatings were analyzed by SEM and TEM. The experimental results indicate that TWAS droplets are the process of explosive breakup or two steps breakup. Morphology of the TWAS prepared Ni-20wt.\%Al and Ni-5wt.\%Al particles was accordingly characterized by SEM. The phase compositions of the Ni-Al particles were obtained by EDS. By testing the velocity of sprayed particles, the change rule of particles with spray pressure was obtained. Ni twins are discovered in the Ni-Al coating due to rapid cooling in TWAS process.
\end{abstract}

Keywords: arc spraying, droplet, atomization, morphology, composition coating.

\section{Introduction}

The principle of the twin-wire arc spraying (TWAS) technique for preparing composite coatings is that the wire tip is melted and sprayed on a fine droplet through dry compressed air ${ }^{1}$. The state of droplets affects the structure and properties of coatings. Generally in TWAS, the higher the velocity of droplet particles is, the higher the coating quality is. At high velocity region, the droplet deformation and breakup is quite complicate ${ }^{2,3}$. The research for the droplet breakup through droplet morphology analysis is necessary for optimizing the TWAS thus improving the properties of coatings ${ }^{4-6}$.

Weng $\mathrm{KW}^{7}$ and Blackwell $\mathrm{BC}^{8}$ had investigated the behavior of droplets flight in low velocity region, for instance in natural air flow. The droplets cross over the changed stages continuously with bag breakup, shock breakup, shear breakup, multi-pattern breakup and explosive breakup. Kelkar $\mathrm{M}^{9}$ explicated that the first and the second dispersed droplets were formed during the droplets atomization. Wang $\mathrm{JX}^{10}$ calculated the atomization behavior and the dynamic characteristics of spraying droplets, and the deformation and solidification behavior of droplets impacting on the substrate. No other literature has been reported. The size of dispersed droplet particles follows a simple normal distribution. The final Reynolds number of the flying droplet is mainly determined by the pressure of atomized gas. The porosity, surface roughness and bonding strength of coatings is affected by the atomization behaviors of the molten droplets ${ }^{11-13}$. The porosity and the surface roughness of the coating reduce with the increase of both temperature and velocity of the molten particles. The flat deformation occurs during the process of spraying particles impacting on the substrate. The higher the impact velocity of the particles is, the stronger the bonding force of coating is. It is quite significant to study atomization characteristics of droplets with a high impact velocity ${ }^{14-17}$. In this paper, the VOF method is adopted to track the interface and the free surface of the collision between the substrate and the droplets. Through characterization of droplets atomization of a TWAS Ni-Al, the droplets breakup and their morphologies were experimentally studied. At the same time, the micro structure and the morphology of the composite coatings were analyzed. 


\section{Mathematical Computation Model of TWAS}

The interaction among droplets is neglected during the flight of droplets. The conveyed characteristics are introduced to describe spraying droplet particles in the air by single droplet, double droplets and three droplets separately. Assuming droplet particles are spherical, and the high-velocity air flow is isothermal and isokinetic. The heat transfer of the droplets mainly includes the radiation and the convection transfer between the air flow and the droplet particles.

According to conservation equation, combined with $k$ - $\varepsilon$ turbulence model and VOF dual-phase flow model, two dimensional governing equations of droplet breakup in gas flow are the following general forms ${ }^{18}$.

$$
\begin{aligned}
& \frac{\partial}{\partial t}(\rho \phi)+\frac{\partial}{\partial x}(\rho u \phi)+\frac{\partial}{\partial y}(\rho u \phi)= \\
& =\frac{\partial}{\partial x}\left(\Gamma_{\phi} \frac{\partial \phi}{\partial x}\right)+\frac{\partial}{\partial y}\left(\Gamma_{\phi} \frac{\partial \phi}{\partial y}\right)+S_{\phi}
\end{aligned}
$$

Where $\phi$ is general dependent variable, $\Gamma_{\phi}$ is transport coefficient, and $\mathrm{S}_{\phi}$ is source term. They are declared in Table 1 for details.

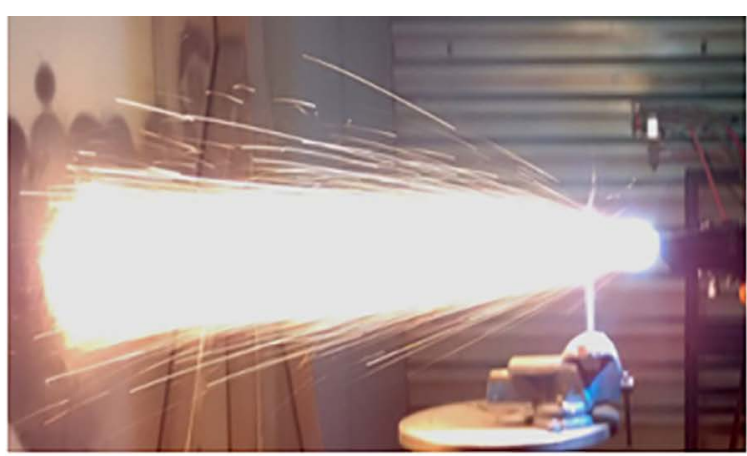

(a) Actual spraying flame flow
In Table $1, \rho=\alpha_{1} \rho_{1}+\left(1-\alpha_{1}\right) \rho_{2} ; F_{x}, F_{y}$ is interaction force of interphase.

$$
\begin{gathered}
G_{k}=\mu_{T}\left[2\left(\frac{\partial u}{\partial x}\right)^{2}+2\left(\frac{\partial v}{\partial y}\right)^{2}+2\left(\frac{\partial u}{\partial y}+\frac{\partial v}{\partial x}\right)^{2}\right] \\
G_{b}=-\beta \rho\left(g_{x} \frac{\mu_{T}}{\sigma_{T}} \frac{\partial T}{\partial x}+g_{y} \frac{\mu_{T}}{\sigma_{T}} \frac{\partial T}{\partial y}\right)
\end{gathered}
$$

Where $\mu_{\mathrm{e}}=\mu+\mu_{\mathrm{T}}, \mu_{\mathrm{e}}$ is effective viscosity coefficient; $\mu_{\mathrm{T}}=$ $\mathrm{c}_{\mu} \rho \mathrm{k}^{2} / \varepsilon, \mu_{\mathrm{T}}$ is turbulent viscosity coefficient; $\sigma_{\mathrm{k}}, \sigma_{\varepsilon}$ is turbulent Prandl number. The constants in the model: $\mathrm{c}_{\mu}=0.09, \mathrm{c}_{1}=1.44$, $c_{2}=1.92, \sigma_{k}=1, \sigma_{\varepsilon}=1.33, \sigma_{\mathrm{T}}=1$.

Fig. 1a shows a schematic diagram of the flame flow during the process of twin-wire arc spraying. The flare angle is about 15 degrees. According to the characteristics of droplet deformation and breakup in the air flow, the computational model is shown in Fig 1b. Droplets enter the computational domain filled with gas, and fly from the right border. An isosceles trapezoid of $20 \times 33 \times 50 \mathrm{~mm}^{3}$ is selected as the computation area. The grid is divided into $200 \times 500$ $\mathrm{mm}^{2}$. The droplet diameters are $0.8 \mathrm{~mm}, 1.6 \mathrm{~mm}, 2.4 \mathrm{~mm}$ and $3.2 \mathrm{~mm}$, respectively.

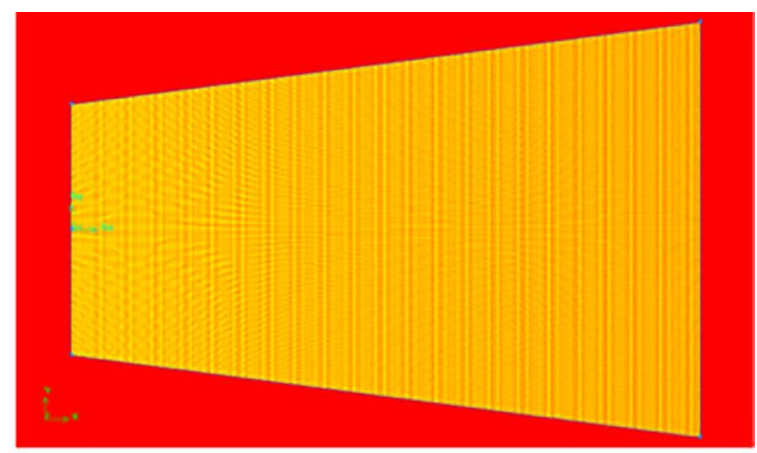

(b) Calculation model grid

Figure 1. Diagram of arc spraying flame flow (a) and diagram of calculation model grid (b).

Table 1. General form of the governing equations and meaning of universal variables.

\begin{tabular}{cccc}
\hline Equation & $\phi$ & $\boldsymbol{\Gamma}_{\phi}$ & $\boldsymbol{S}_{\phi}$ \\
\hline Continuity & 1 & 0 & 0 \\
x-momentum & $\mathrm{u}$ & $\mu_{\mathrm{e}}$ & $-\frac{\partial P}{\partial x}+\frac{\partial}{\partial x}\left(\mu_{e} \frac{\partial u}{\partial x}\right)+\frac{\partial}{\partial y}\left(\mu_{e} \frac{\partial v}{\partial x}\right)+\Delta p g_{x}+F_{x}$ \\
y-momentum & $\mathrm{v}$ & $\mu_{\mathrm{e}}$ & $-\frac{\partial P}{\partial y}+\frac{\partial}{\partial y}\left(\mu_{e} \frac{\partial u}{\partial y}\right)+\frac{\partial}{\partial x}\left(\mu_{e} \frac{\partial u}{\partial y}\right)+\Delta p g_{y}+F_{y}$ \\
Turbulent energy & $\mathrm{k}$ & $\mu_{\mathrm{e}} / \sigma_{\mathrm{k}}$ & $\mathrm{G}_{\mathrm{k}}+\mathrm{G}_{\mathrm{b}}-\rho \varepsilon$ \\
Dissipation rate & $\varepsilon$ & $\mu_{\mathrm{e}} / \sigma_{\varepsilon}$ & $\varepsilon\left(\mathrm{c}_{1} \mathrm{G}_{\mathrm{k}}-\mathrm{c}_{2} \rho \varepsilon\right) / \mathrm{k}$ \\
Enthalpy & $\mathrm{h}$ & $\mu_{\mathrm{e}} / \sigma_{\mathrm{T}}$ & $-\mathrm{q}_{\mathrm{T}}$ \\
Volume fraction & - & - & $\frac{\partial \alpha_{1}}{\partial t}+u \frac{\partial \alpha_{1}}{\partial x}+v \frac{\partial \alpha_{1}}{\partial y}=0$
\end{tabular}




\section{Droplet Breakup Behavior of Atomization}

Atomization process of arc spraying is a complicated process. The dynamics of droplet formation is modulated by both the arc and the atomization gas. Thermo physical parameters for numerical analysis are listed in Table $2^{19}$.

Fig. 2 shows the process of deformation and breakup of a droplet with initial diameter $\varnothing 1.6 \mathrm{~mm}$ and at atomization gas pressure $0.5 \mathrm{MPa}$ at different times. In the paper, all the color bar units are temperature $\mathrm{K}$. The droplet particle is not crescent, but the center of the droplet begins to break at $\sim 10$ $\mu \mathrm{s}$, because of the larger atomization gas pressure. The droplet particle undergoes a transition from the first breakup to the second breakup process between $20 \mu$ s and $30 \mu$ s. The second breakup is completed after $30 \mu \mathrm{s}$, and the atomized particles of the region become fewer at $70 \mu \mathrm{s}$. The breakup particles quickly fly out of the computational region subsequently. The droplet particle is firstly deformed, and then proceeded the first breakup, followed by the second breakup during this process.

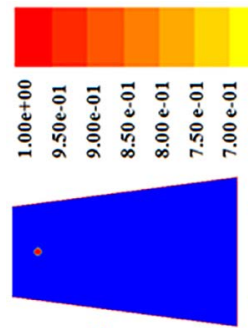

$0 \mu \mathrm{s}$

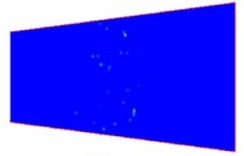

$30 \mu \mathrm{s}$

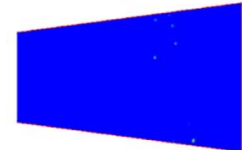

$60 \mu \mathrm{s}$

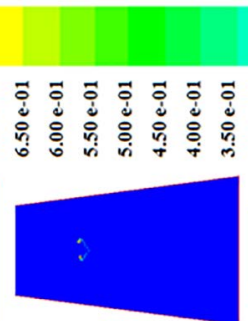

$10 \mu \mathrm{s}$

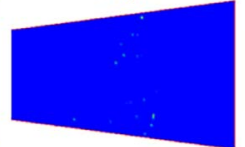

$40 \mu \mathrm{s}$

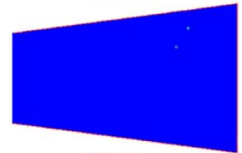

$70 \mu \mathrm{s}$
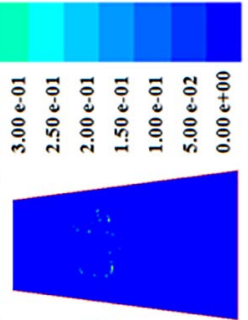

$20 \mu s$

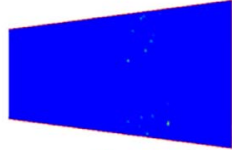

$50 \mu \mathrm{s}$

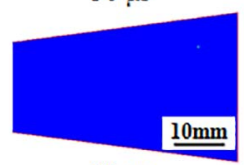

$80 \mu \mathrm{s}$

Figure 2. Characteristics of change of TWAS atomized droplet breakup process with time.

The process of deformation and breakup of the droplet at $50 \mu \mathrm{s}$ with the diameter of $1.6 \mathrm{~mm}$ and the pressure range of $0.2 \mathrm{MPa} \sim 0.7 \mathrm{MPa}$ is shown in Fig. 3. At $0.2 \mathrm{MPa}$, the droplet particle suffers the second breakup, so the first breakup is before $50 \mu \mathrm{s}$. After $0.2 \mathrm{MPa}$ and at $50 \mu \mathrm{s}$, with the pressure increase, the droplet particle completely breaks up, and finally forms a stable phase.

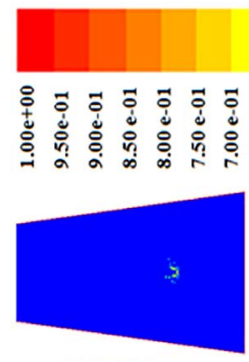

$0.2 \mathrm{MPa}$

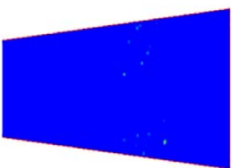

$0.5 \mathrm{MPa}$

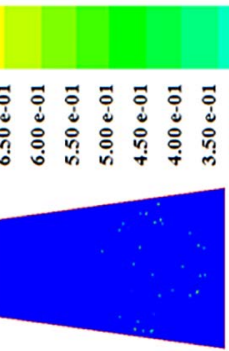

$0.3 \mathrm{MPa}$

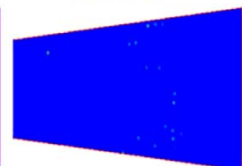

$0.6 \mathrm{MPa}$
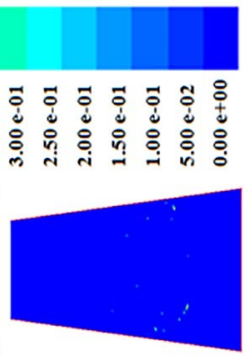

$0.4 \mathrm{MPa}$

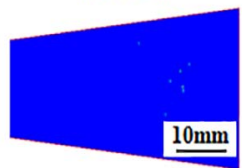

$0.7 \mathrm{MPa}$
Figure 3. Characteristics of change of TWAS atomized droplet breakup process with pressure.

Fig. 4 shows the process of deformation and breakup of double droplets with diameter $\varnothing 1.6 \mathrm{~mm}$ and at atomization gas pressure $0.5 \mathrm{MPa}$ at different times. Schematic diagram of three droplets deformation and breakup process at different times with initial diameter $\varnothing 1.6 \mathrm{~mm}$ and at atomization gas pressure 0.5 MPa are shown in Fig. 5 and Fig. 6.

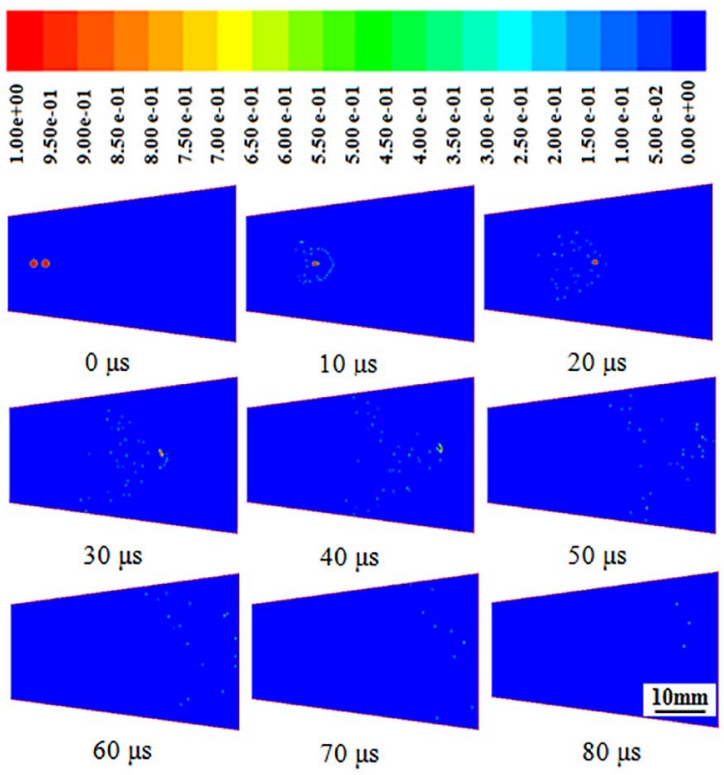

Figure 4. Time dependence of atomized double droplets of arrangement in line breakup process.

Table 2. Thermo physical parameters for numerical analysis.

\begin{tabular}{ccccccc}
\hline Materials & $\begin{array}{c}\text { Melting point } \\
(\mathrm{K})\end{array}$ & $\begin{array}{c}\text { Density } \\
\left(\mathrm{kg} \cdot \mathrm{m}^{-3}\right)\end{array}$ & $\begin{array}{c}\text { Specific heat } \\
\left(\mathrm{J} \cdot \mathrm{kg}^{-1} \cdot \mathrm{K}^{-1}\right)\end{array}$ & $\begin{array}{c}\text { Thermal conductivity } \\
\left(\mathrm{W} \cdot \mathrm{m}^{-1} \cdot \mathrm{K}^{-1}\right)\end{array}$ & $\begin{array}{c}\text { Kinematic viscosity } \times 10^{6} \\
(\mathrm{~Pa} \cdot \mathrm{s})\end{array}$ & $\begin{array}{c}\text { Molar mass } \\
\left(\mathrm{g} \cdot \mathrm{mol}^{-1}\right)\end{array}$ \\
\hline Air & - & 1.225 & 1006 & 0.024 & 113.3 & 29 \\
Ni-Al & 1728 & 8591 & 481 & 97.273 & 5000 & 57.1 \\
\hline
\end{tabular}




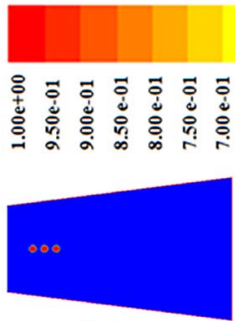

$0 \mu \mathrm{s}$

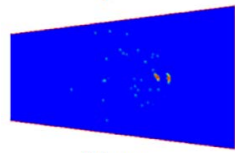

$30 \mu \mathrm{s}$

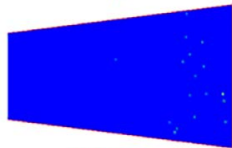

$60 \mu \mathrm{s}$

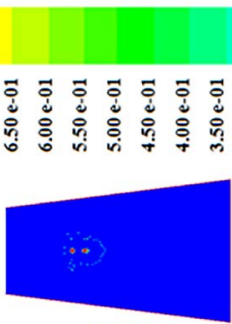

$10 \mu \mathrm{s}$

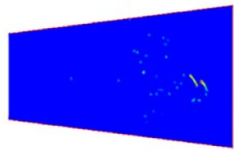

$40 \mu \mathrm{s}$

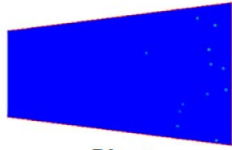

$70 \mu \mathrm{s}$
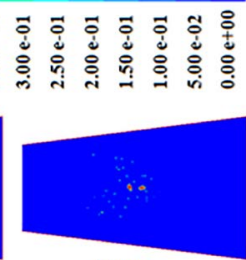

$20 \mu s$

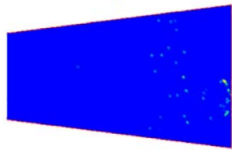

$50 \mu \mathrm{s}$

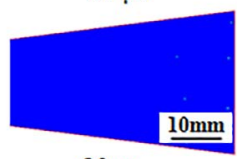

$80 \mu \mathrm{s}$
Figure 5. Time dependence of atomized three droplets of arrangement in line breakup process.

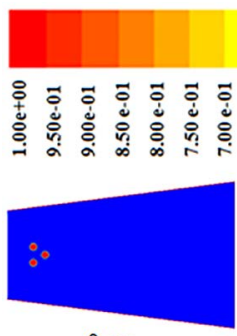

0 us

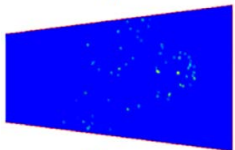

$30 \mu \mathrm{s}$

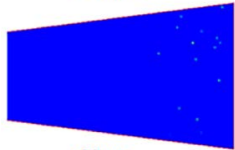

$60 \mu \mathrm{s}$

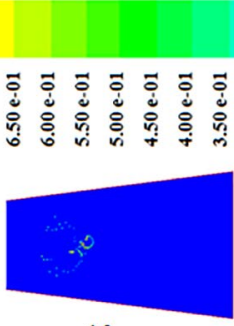

$10 \mu \mathrm{s}$

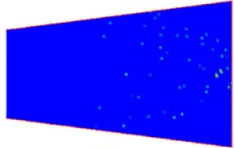

$40 \mu \mathrm{s}$

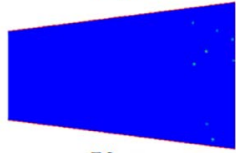

$70 \mu \mathrm{s}$
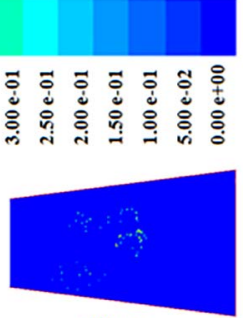

$20 \mu \mathrm{s}$

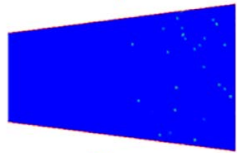

$50 \mu \mathrm{s}$

$80 \mu \mathrm{s}$

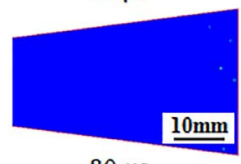

Figure 6. Time dependence of atomized three droplets of arrangement in line breakup process.

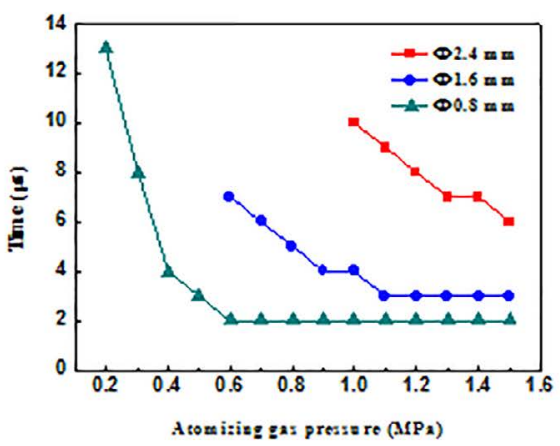

(a) Gas pressure and explosive breakup time
Double droplets and three droplets are arranged in line, however the first droplet is affected by the latter droplet. At the beginning, the first droplet is not broken enough and will be broken into large droplets at the later stage of flight. The droplets of arrangement in triangle are less affected by the front droplets and the latter droplets than the droplets of arrangement in line. Between $20 \mu \mathrm{s}$ and $40 \mu \mathrm{s}$, droplet particles undergo a transition from the first breakup to the second breakup process. The second breakup is completed at $50 \mu \mathrm{s}$, and the particles in the region become a fewer at $80 \mu$ s than that of single droplet particle. Subsequently, the breakup particles quickly fly out of the computational region. During this process, the droplet particles are firstly deformed, and then the first breakup, followed by the second breakup.

Fig. 7a indicates relationships between gas pressure and explosive breakup time. The explosive breakup of droplets is affected by atomized gas pressure and droplet diameter. When the atomization pressure is greater than $0.6 \mathrm{MPa}$, the droplets with a diameter of $0.8 \mathrm{~mm}$ are explosive breakup at $2 \mu \mathrm{s}$, and tend to be stable. Droplets with diameter of $2.4 \mathrm{~mm}$ will be explosive breakup when the atomization pressure is 1.0 $\mathrm{MPa}$. When the atomization pressure of the droplet diameter of $3.2 \mathrm{~mm}$ is less than $1.5 \mathrm{MPa}$, it is very difficult to form explosive breakup. The atomization pressure or velocity of droplets determines breakup characteristic of the droplets.

Fig. 7b indicates calculated relationships between atomizing gas pressure and gas velocity. At $0.2 \mathrm{MPa}$, the velocity of the outlet gas is $571 \mathrm{~m} / \mathrm{s}$. At $0.5 \mathrm{MPa}$, the velocity of the outlet gas is $904 \mathrm{~m} / \mathrm{s}$. At $0.8 \mathrm{MPa}$, the velocity of the outlet gas reaches $1143 \mathrm{~m} / \mathrm{s}$. With the increase of atomizing gas pressure, the velocity of outlet gas increases. The atomizing gas pressure is approximately linear with the gas velocity. The actual spraying particles velocity can merely reach $15 \%$ $\sim 45 \%$ of the atomizing gas velocity, even lower because of the different materials and spraying distance. The droplet particles velocity is much faster than the sonic velocity, satisfies the basic requirements of coating during the spraying process. A larger pressure can result in a faster cooling of the broken particles, but the bonding strength will be decreased after final solidification ${ }^{20}$.

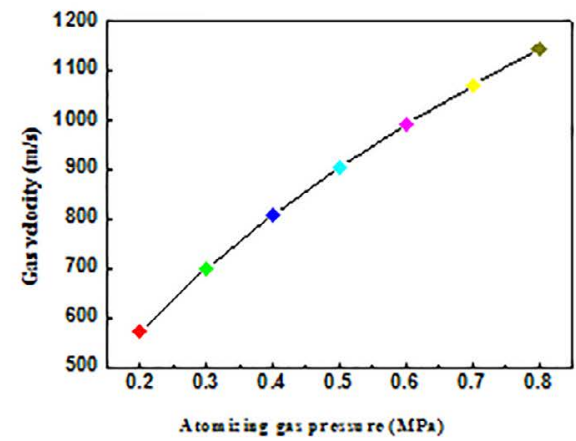

(b) Gas pressure and gas velocity

Figure 7. Change of gas pressure with explosive breakup time and gas velocity and (a) and (b). 


\section{Characteristics and Morphologies of Particles in TWAS Ni-Al}

The spraying system of a Praxair/TAFA controller is used in the experiment. Twin-wire arc spraying gun is model 9935 , and which is clamped by the manipulator when spraying. Generally, Ni-5wt.\%Al is used as the bond coat, while Ni$20 \mathrm{wt} . \% \mathrm{Al}$ is used as the surface coat ${ }^{21,22}$. The Ni-Al powder is collected by using water under different technological parameters. Processing parameters of the Ni-Al powders are listed in Table 3. The Ni-Al powder is precipitated and collected under $373 \mathrm{~K}$ drying for $1 \mathrm{~h} \sim 2 \mathrm{~h}$. The cross-section and surface morphology of the different $\mathrm{Ni}-\mathrm{Al}$ powders is observed by SEM. Fig. 8 shows collection process of the twin-wire arc sprayed Ni-Al powder. Some special particles are conducted the surface EDS and line scanning.

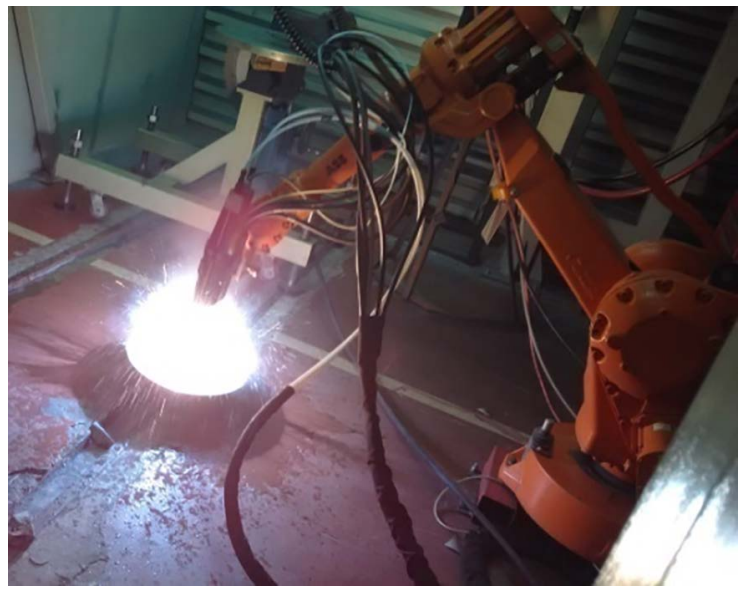

Figure 8. Powder collection process of twin-wire arc sprayed Ni-Al.

Fig. 9 shows morphology of the TWAS Ni-5wt.\%Al powder and Ni-20wt.\%Al powder under different $0.5 \mathrm{MPa}$ gas pressure. The particle size is mostly less than $50 \mu \mathrm{m}$ and possesses a high spherical degree. Particle size of Ni5 wt.\%Al is larger than that of Ni-20wt.\%Al. This is mainly due to the fact that $\mathrm{Ni}-20 \mathrm{wt} . \% \mathrm{Al}$ is cored wire. There is no evident difference in the shape of molten particles produced during the spray process of two kinds of wires.

The surface morphology of Ni-Al powder for $0.5 \mathrm{MPa}$ and line scanning and energy spectrum analysis of particles in twin-wire arc sprayed Ni-Al are shown in Fig. 10. Different parts of ellipsoidal particles are shown as $1 \#, 2 \#$ and $3 \#$ in Fig. 10a. There is almost no obvious difference for molten particles, which is composed of $\mathrm{Al}_{2} \mathrm{O}_{3}$ in the middle grey part, $\mathrm{Ni}-\mathrm{Al}$ compounds and $\mathrm{NiO}$ in the white parts on both sides.
Fig. 11a shows that the cross-section morphology of a Ni-Al particle exhibits a special shape, including the dendrite type due to rapid cooling, which mostly consists of $\mathrm{Al}_{2} \mathrm{O}_{3}$ and $\mathrm{NiAl}(1 \#)$ and $\mathrm{Ni}$ solid solution (2\#), and it is shown in Fig. $11 \mathrm{~b}$.

Fig. 12a shows that the cross-section morphology of a Ni-Al particle exhibits a special shape, including the dendrite type due to rapid cooling, which mostly consists of $\mathrm{Al}_{2} \mathrm{O}_{3}(1 \#)$ and $\mathrm{Ni}_{3} \mathrm{Al}(2 \#)$, and it is shown in Fig. 12b.

It will play an important role in directing the design of spraying processes by analyzing the morphologies of particles in the atomization process ${ }^{23}$. The larger Ni-Al particle size for the decrease of atomization pressure makes the surface roughness become larger, and which improves the wear resistance of the coating. Contrarily, the Ni-Al particle size reduces for the increase of atomization pressure, accordingly, the smaller porosity of the coating makes the bonding strength between substrate and coating increase.

\section{Droplet Velocity and Microstructure of Composition Coating}

The velocity of Ni-Al particles was measured by ISSO-1 instrument. The measurement results are shown in Fig. 13. Due to differences in density, the velocity of $\mathrm{Ni-20wt. \% Al} \mathrm{is} \mathrm{larger} \mathrm{than} \mathrm{that} \mathrm{of} \mathrm{Ni-5wt. \% Al,} \mathrm{which}$ is shown in Fig. 13a. Fig. 13b shows that the particles velocity increases with the increase of spraying distance until it tends to be stable and then decreases. With the gas pressure increasing, the particles velocity increases. It can be confirmed that the spraying material, gas pressure and spraying distance are the main factors leading to the different velocity of the particles. The droplets deformation and breakup process can fully demonstrate the droplets change characteristics during the twin-wire arc spraying process. The atomization law of TWAS droplets is verified by the particles velocity characteristics, and which provides a reference for obtaining the best spraying process parameters ${ }^{24}$.

The coating substrate is 6061-T6 aluminum alloy. Before spraying, the substrate needs sandblasting and coarsening. The thickness of the coating is controlled by the gun speed. The overlap between the coating and the coating should be appropriate. The temperature of the substrate could not exceed $473 \mathrm{~K}$ during arc spraying process. Processing parameters of twin-wire arc spraying are listed in Table 4.

Table 3. Processing parameters of achieving Ni-Al powder.

\begin{tabular}{ccccccc}
\hline Spraying materials & $\begin{array}{c}\text { Spraying voltage } \\
(\mathrm{V})\end{array}$ & $\begin{array}{c}\text { Spraying current } \\
(\mathrm{A})\end{array}$ & $\begin{array}{c}\text { Wire diameter } \\
(\mathrm{mm})\end{array}$ & $\begin{array}{c}\text { Spraying distance } \\
(\mathrm{mm})\end{array}$ & $\begin{array}{c}\text { Spraying time } \\
(\mathrm{s})\end{array}$ & $\begin{array}{c}\text { Air pressure } \\
(\mathrm{MPa})\end{array}$ \\
\hline Ni-5wt.\%Al & 38 & 260 & $\varnothing 1.6$ & 150 & 30 & $0.3 / 0.4 / 0.5$ \\
Ni-20wt.\%Al & 36 & 240 & $\varnothing 1.6$ & 150 & 30 & $0.3 / 0.4 / 0.5$ \\
\hline
\end{tabular}




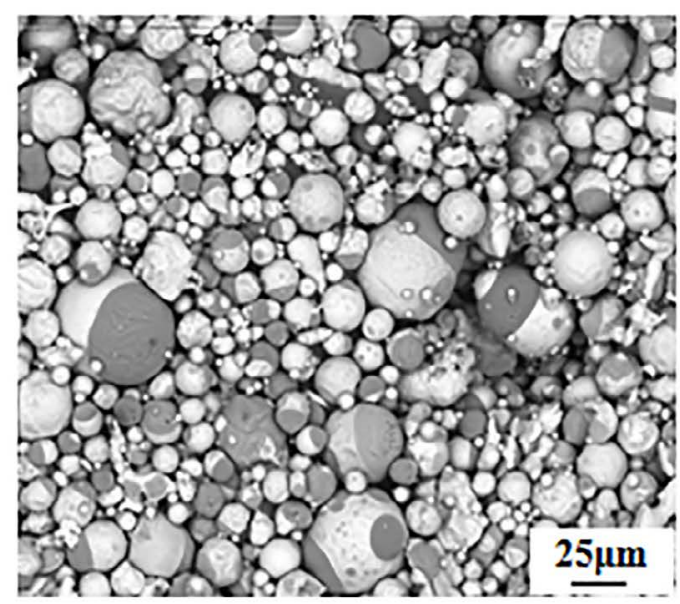

(a) Ni-5wt.\%Al

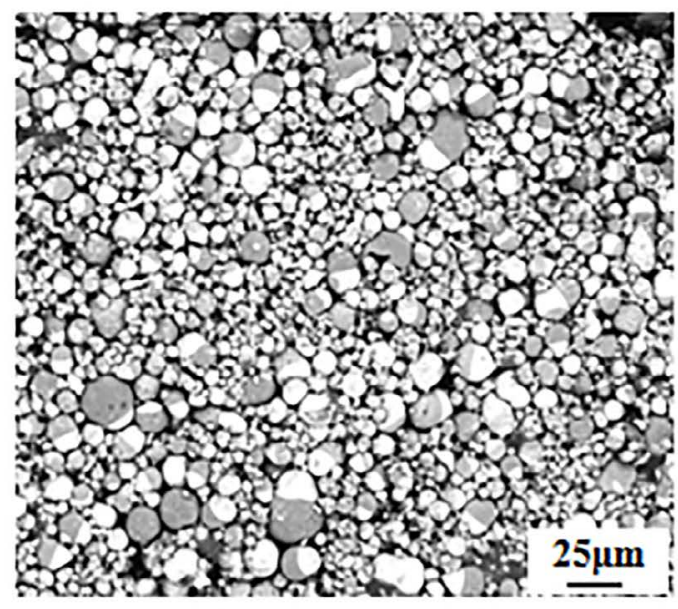

(b) Ni-20wt.\%.Al

Figure 9. Morphology of TWAS Ni-Al powder under 0.5 MPa pressure.

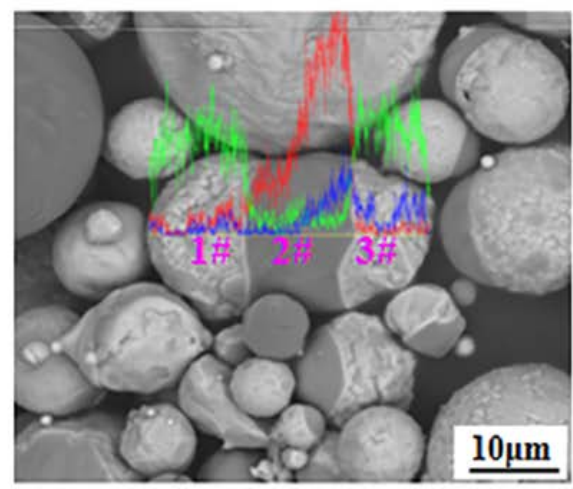

(a) Ni-Al particles morphology
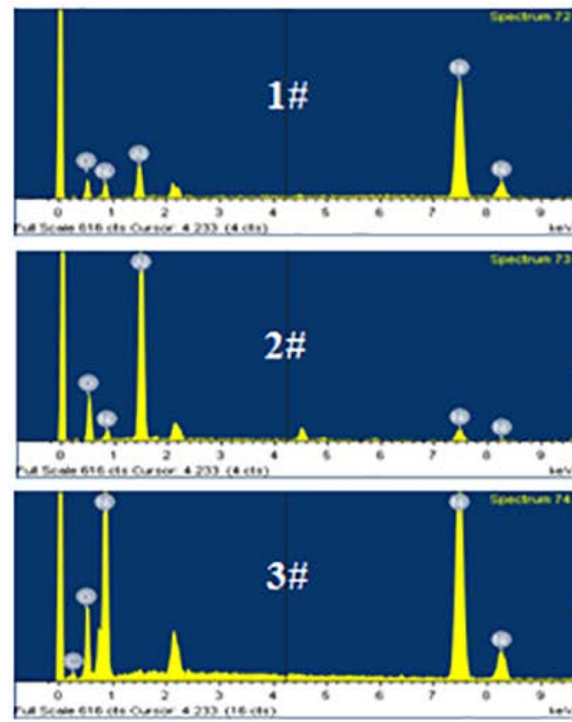

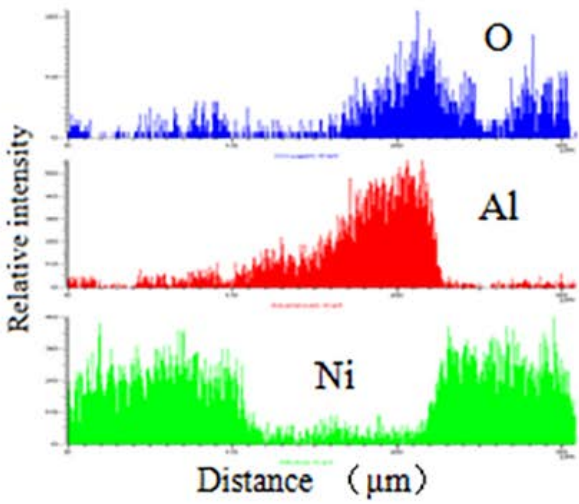

(b) Linear scanning

\begin{tabular}{|c|c|c|}
\hline Element & Weight \% & Atomic \% \\
\hline $\mathrm{OK}$ & 5.46 & 16.22 \\
\hline $\mathrm{Al} \mathrm{K}$ & 7.44 & 13.14 \\
\hline $\mathrm{NiK}$ & $\$ 7.10$ & 70.64 \\
\hline Totals & 100.00 & \\
\hline Element & Weight \% & Atomic \% \\
\hline $\mathrm{OK}$ & 32.52 & 48.39 \\
\hline Al K & 50.84 & 44.86 \\
\hline $\mathrm{NiK}$ & 16.64 & 6.75 \\
\hline Totals & 100.00 & \\
\hline Element & Weight \% & Atomic \% \\
\hline OK & 11.70 & 32.61 \\
\hline Al $\mathrm{K}$ & 0.37 & 0.61 \\
\hline $\mathrm{Ni} \mathrm{K}$ & 87.93 & 66.78 \\
\hline Totals & 100.00 & \\
\hline
\end{tabular}

(c) Energy spectrum analysis

Figure 10. Morphology and line scanning and energy spectrum analysis (a) and (b) and (c). 


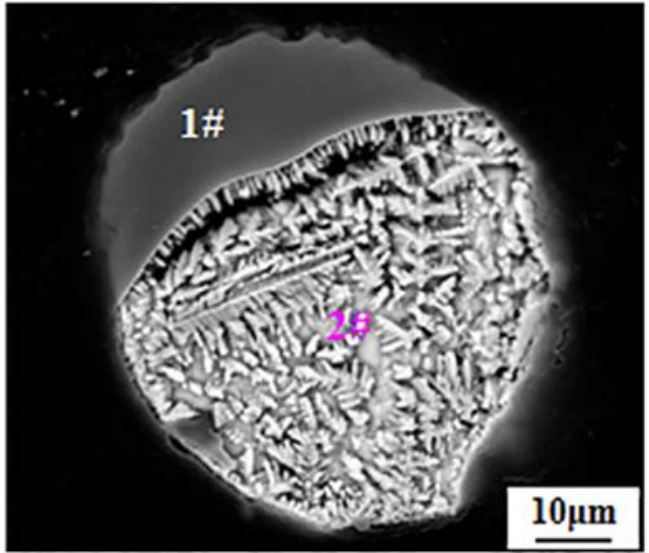

(a) A Ni-Al particle section morphology

\begin{tabular}{|c|c|c|}
\hline Element & Weight $\%$ & Atomic $\%$ \\
\hline $\mathrm{OK}$ & 33.14 & 50.75 \\
\hline $\mathrm{Al} \mathrm{K}$ & 43.50 & 39.50 \\
\hline $\mathrm{NiK}$ & 23.36 & 9.75 \\
\hline Totals & 100.00 & \\
\hline
\end{tabular}

\begin{tabular}{ccc}
\hline Element & Weight $\%$ & Atomic $\%$ \\
\hline Ni K & 100.00 & 100.00 \\
Totals & 100.00 & \\
\hline
\end{tabular}

(b) Energy spectrum analysis

Figure 11. Energy spectrum analysis of powder section of TWAS Ni-Al (a) and (b).

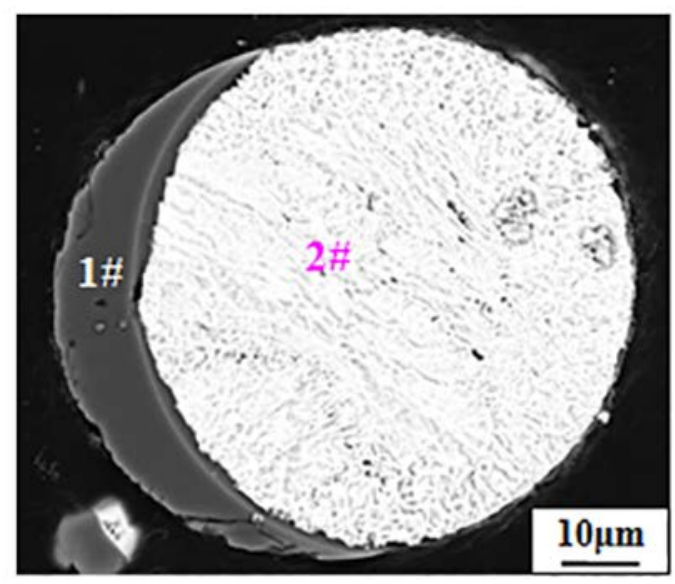

(a) A Ni-Al particle section morphology

\begin{tabular}{ccc}
\hline Element & Weight \% & Atomic \% \\
\hline O K & 40.05 & 52.98 \\
Al K & 59.95 & 47.02 \\
Totals & 100.00 & \\
\hline
\end{tabular}

\begin{tabular}{|c|c|c|}
\hline Element & Weight $\%$ & Atomic \% \\
\hline $\mathrm{Al} \mathrm{K}$ & 13.09 & 24.69 \\
\hline $\mathrm{Ni} \mathrm{K}$ & 86.91 & 75.31 \\
\hline Totals & 100.00 & \\
\hline
\end{tabular}

(b) Energy spectrum analysis

Figure 12. Energy spectrum analysis of powder section of TWAS Ni-Al (a) and (b).

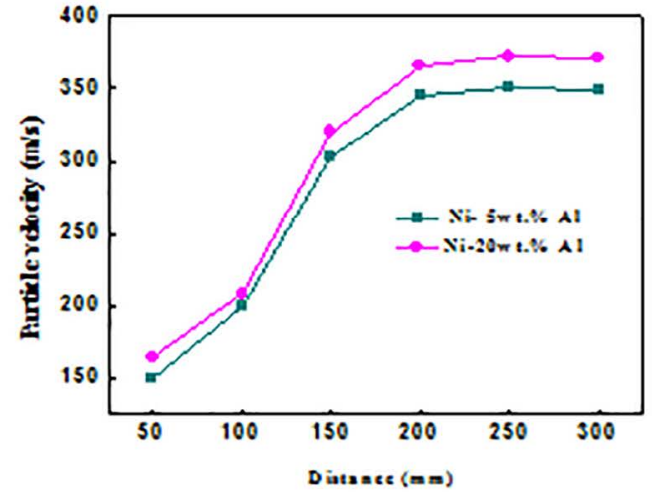

(a) $0.5 \mathrm{MPa}$ pressure

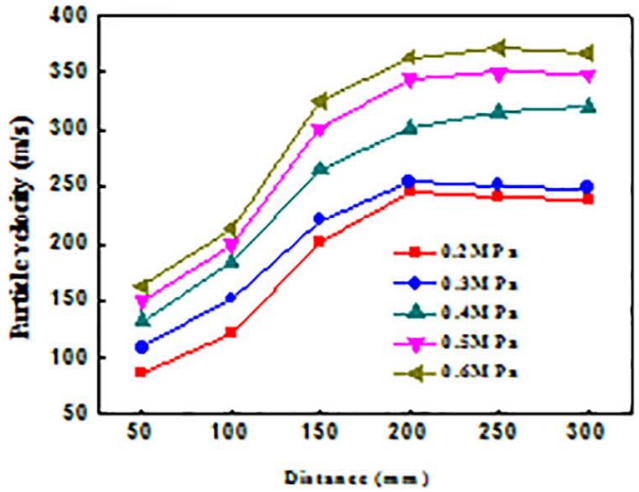

(b) $0.2 \mathrm{MPa} \sim 0.6 \mathrm{MPa}$ pressure

Figure 13. Relationships between spraying distance and particle velocity of TWAS (a) and (b). 
Table 4. Processing parameters of TWAS technique.

\begin{tabular}{cccccccc}
\hline $\begin{array}{c}\text { Spraying } \\
\text { materials }\end{array}$ & $\begin{array}{c}\text { Spraying voltage } \\
(\mathrm{V})\end{array}$ & $\begin{array}{c}\text { Spraying current } \\
(\mathrm{A})\end{array}$ & $\begin{array}{c}\text { Wire diameter } \\
(\mathrm{mm})\end{array}$ & $\begin{array}{c}\text { Air pressure } \\
(\mathrm{MPa})\end{array}$ & $\begin{array}{c}\text { Spraying distance } \\
(\mathrm{mm})\end{array}$ & $\begin{array}{c}\text { Gun speed } \\
\left(\mathrm{mm} \cdot \mathrm{s}^{-1}\right)\end{array}$ & $\begin{array}{c}\text { Coating thickness } \\
(\mathrm{mm})\end{array}$ \\
\hline Ni-5wt.\%Al & 38 & 260 & $\varnothing 1.6$ & 0.5 & 150 & 300 & 0.15 \\
Ni-20wt.\%Al & 36 & 240 & $\varnothing 1.6$ & 0.5 & 50 & 300 & 0.35 \\
\hline
\end{tabular}

The Ni-Al coating was successfully prepared by twinwire arc spraying with the Ni-5wt.\%Al alloy as the bonding layer and $\mathrm{Ni}-20 \mathrm{wt} . \% \mathrm{Al}$ as the surface layer. Microstructure and morphology of the coating were observed by SEM, as shown in Fig. 14a and Fig. 14b. The cross-sectional morphology of the coatings shows a multiphase interlaced layered structure with a smooth interface between the coatings and the substrate and a close bonding with the substrate.
The coating surface shows relatively homogeneous morphology. The surface of the coating is uneven and the roughness is large.

Twin crystal morphology and electron diffraction of NiAl coatings are shown in Fig. 15. Ni twins are discovered in the Ni-Al coating, which is shown in Fig. 15a. This is mainly due to the rapid cooling of particles during spraying. Twin zone electron diffraction displays that crystal belt axis is [011], twin axis is [111], and twin surface is (111).

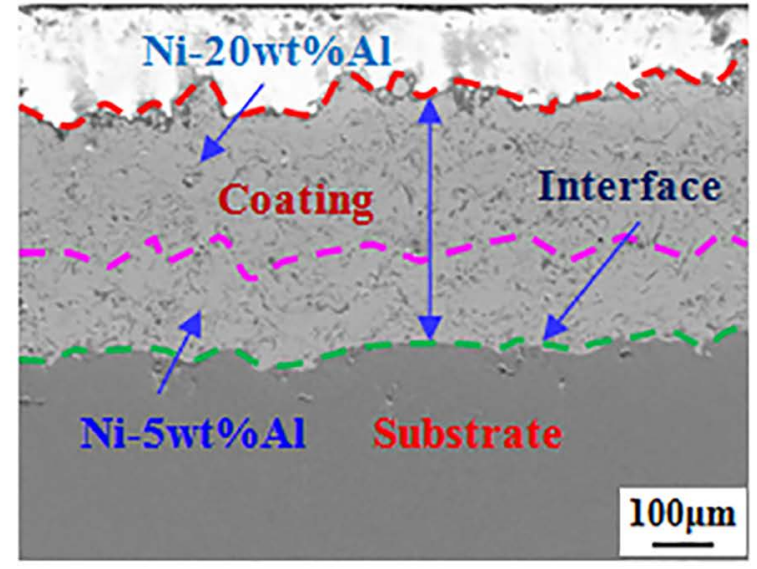

(a) Cross-section morphology

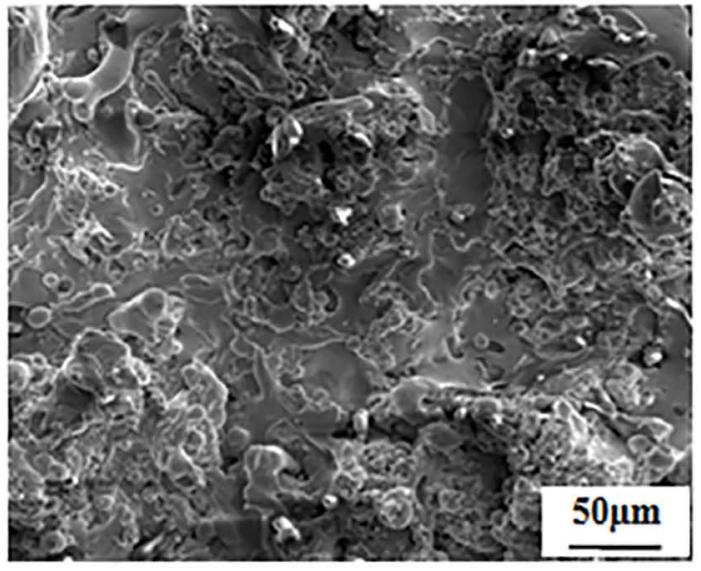

(b) Surface morphology

Figure 14. Cross-section and the surface morphology of Ni-Al coatings (a) and (b).

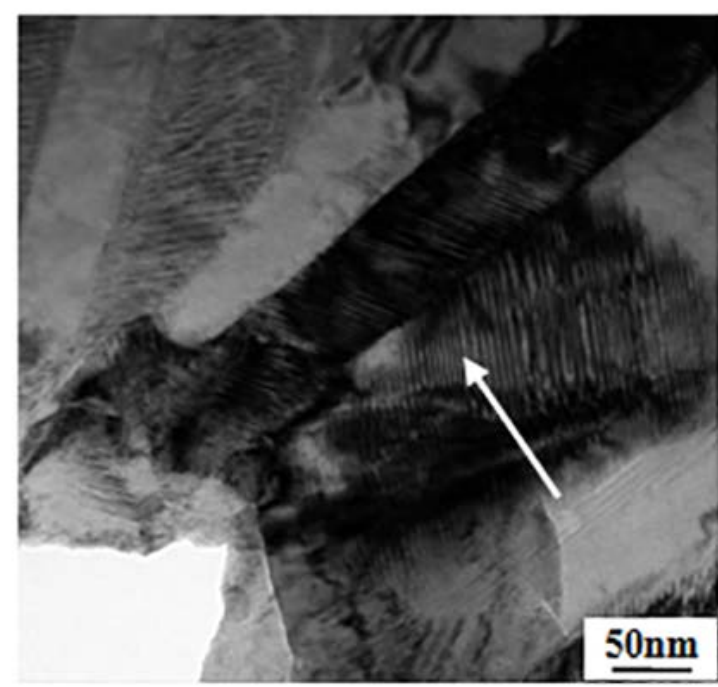

(a) Twin crystal

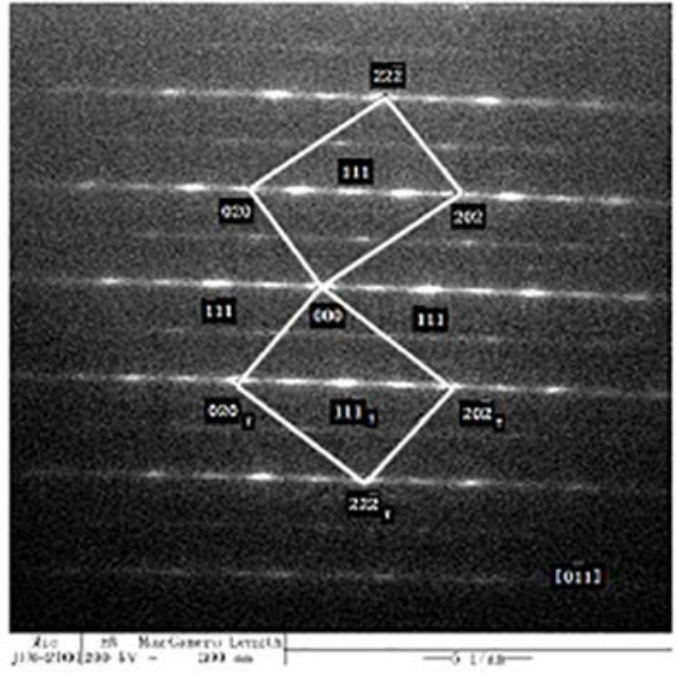

(b) Twin crystal SADP

Figure 15. Twin crystal morphology and electron diffraction of Ni-Al coatings (a) and (b). 
By electron probe energy spectrum analysis, the coating is mainly composed of $\mathrm{Ni}, \mathrm{Al}$ and $\mathrm{O}$.

\section{Conclusions}

The characteristics of TWAS droplet atomization are a breakup model possessing both two stages breakup at the lower velocity and explosive breakup at high velocity based on VOF dual-phase flow model.

The main phase of Ni-Al particles obtains Ni solid solution, $\mathrm{Ni}-\mathrm{Al}$ compounds, $\mathrm{NiO}$ and $\mathrm{Al}_{2} \mathrm{O}_{3}$. The particle size is mostly less than $50 \mu \mathrm{m}$ and possesses a high spherical degree. The cross-section morphology of particles displays the characteristics of dendrite structure.

The particles velocity increases with the increase of spraying distance until it tends to be stable and then decreases. With the gas pressure increasing, the particles velocity increases. $\mathrm{Ni}$ twins are discovered in the $\mathrm{Ni}-\mathrm{Al}$ coating due to rapid cooling.

\section{Acknowledgements}

The research work is supported by the Natural Science Foundation of Heilongjiang Province of China. Its granted number is No. E2018054. J.X. Wang would like to thank everyone who helped the fund project.

\section{References}

1. Ma PC, Lv Y, Ihme M. An entropy-stable hybrid scheme for simulations of transcritical real-fluid flows. Journal of Computational Physics. 2017;340:330-357. DOI: 10.1016/j. jcp.2017.03.022

2. Martínez-Calvo A, Rubio-Rubio M, Sevilla A. The nonlinear states of viscous capillary jets confined in the axial direction. Journal of Fluid Mechanics. 2018;834:335-358. DOI: 10.1017/ jfm.2017.706

3. Wolinski H, Kolb D, Hermann S, Koning RI, Kohlwein SD. A role for seipin in lipid droplet dynamics and inheritance in yeast. Journal of Cell Science. 2011;124(22):3894-3904. DOI: $10.1242 /$ jcs.091454

4. Alsharif AM. Drop formation and break-up of rotating viscoelastic liquid jets in the Giesekus model. IMA Journal of Applied Mathematics. 2018;83(1):174-187. DOI: 10.1093/ imamat $/ \mathrm{hxx} 040$

5. Tillmann W, Abdulgader M. Wire composition: its effect on metal disintegration and particle formation in twin-wire arc-spraying process. Journal of Thermal Spray Technology. 2013;22(2-3):352-362. DOI: 10.1007/s11666-012-9870-y

6. Weng KW, Huang YP. Preparation of $\mathrm{TiO}_{2}$ thin films on glass surfaces with self-cleaning characteristics for solar concentrators. Surface and Coatings Technology. 2013;231:201-204. DOI: 10.1016/j.surfcoat.2012.06.058
7. Blackwell BC, Deetjen ME, Gaudio JE, Ewoldt RH. Sticking and splashing in yield-stress fluid drop impacts on coated surfaces. Physics of Fluids. 2015;27(4):043101. DOI: 10.1063/1.4916620

8. Kelkar M, Heberlein J. Wire-arc spray modeling. Plasma Chemistry and Plasma Processing. 2002;22(1):1-25. DOI: 10.1023/A:1012924714157

9. Liu J, Xu X. Direct numerical simulation of secondary breakup of liquid drops. Chinese Journal of Aeronautics. 2010;23(2):153-161. DOI: 10.1016/S1000-9361(09)60199-0

10. Wang JX, Wang YD, Liu JS, Zhang LY, Gao LM, Zheng GH, Shen HX, Sun JF. Microstructure and flight behaviors of droplet and its solidification in twin-wire arc sprayed $\mathrm{Ni}-\mathrm{Al}$ composite coating. Materials Research. 2018;21(3):e20170394. DOI: 10.1590/1980-5373-mr-2017-0394

11. Zhu X, Yang Z, Bi Q. Experimental study on the pressure drop characteristics of steam-water two-phase flow at a low mass velocity in a four-head rifled tube. Applied Thermal Engineering. 2017;122:148-157. DOI: 10.1016/j.applthermaleng.2017.04.162

12. Lipatov II, Polyanin AD. Decomposition and exact solutions of equations of a weakly compressible barotropic fluid. Doklady Physics. 2013;58(3):116-120. DOI: 10.1134/S1028335813030099

13. Elwardany AE, Sazhin SS. A quasi-discrete model for droplet heating and evaporation: application to diesel and gasoline fuels. Fuel. 2012;97:685-694. DOI: 10.1016/j. fuel.2012.01.068

14. Müller T, Sänger A, Habisreuther P, Jakobs T, Trimis D, Kolb T, Zarzalis N. Simulation of the primary breakup of a highviscosity liquid jet by a coaxial annular gas flow. International Journal of Multiphase Flow. 2016;87:212-228. DOI: 10.1016/j. ijmultiphaseflow.2016.09.008

15. Onuaguluchi O, Eren Ö. Cement mixtures containing copper tailings as an additive: durability properties. Materials Research. 2012;15(6):1029-1036. DOI: 10.1590/S151614392012005000129

16. Liu X, Kavanagh J, Matthews A, Leyland A. The combined effects of $\mathrm{Cu}$ and $\mathrm{Ag}$ on the nanostructure and mechanical properties of CrCuAgN PVD coatings. Surface \& Coatings Technology. 2015;284:101-111. DOI: 10.1016/j.surfcoat.2015.08.070

17. Hina S, Hayat T, Asghar S, Hendi AA. Influence of compliant walls on peristaltic motion with heat/mass transfer and chemical reaction. International Journal of Heat \& Mass Transfer. 2012;55(1314):3386-3394. DOI: 10.1016/j.ijheatmasstransfer.2012.02.074

18. Al-Resayes SI. Kinetics analysis for non-isothermal decomposition $\gamma$-irradiated indium acetate. Arabian Journal of Chemistry. 2010;3(3):191-194. DOI: 10.1016/j.arabjc.2010.04.010

19. Dietrich D, Grittner N, Mehner T, Nickel D, Schaper M, Maier HJ, Lampke T. Microstructural evolution in the bonding zones of co-extruded aluminium/titanium. Journal of Materials Science. 2014;49(6):2442-2455. DOI: 10.1007/s10853-013-7912-6

20. Chinnov EA, Ron'Shin FV, Kabov OA. Two-phase flow patterns in short horizontal rectangular microchannels. International Journal of Multiphase Flow. 2016;80:57-68. DOI: 10.1016/j. ijmultiphaseflow.2015.11.006 
21. Wang JX, Liu JS, Zhang LY, Sun JF, Wang ZP. Microstructure and mechanical properties of twin-wire arc sprayed $\mathrm{Ni}-\mathrm{Al}$ composite coatings on 6061-T6 aluminum sheet. International Journal of Minerals, Metallurgy, and Materials. 2014;21(5):469478. DOI: $10.1007 / \mathrm{s} 12613-014-0931-8$

22. Wang JX, Wang GX, Liu JS, Zhang LY, Wang W, Li Z, Wang QX, Sun JF. Microstructure of Ni-Al powders and Ni-Al composite coatings prepared by twin-wire arc spraying. International Journal of Minerals, Metallurgy, and Materials. 2016;23(7):810-818. DOI: $10.1007 / \mathrm{s} 12613-016-1295-\mathrm{z}$
23. Kumar RK, Kamaraj M, Seetharamu S, Pramod T, Sampathkumaran P. Effect of spray particle velocity on cavitation erosion resistance characteristics of HVOF and HVAF processed $86 \mathrm{WC}-10 \mathrm{Co} 4 \mathrm{Cr}$ hydro turbine coatings. Journal of Thermal Spray Technology. 2016;25(6):1-14. DOI: $10.1007 / \mathrm{s} 11666-016-0427-3$

24. Deshmukh A, Vasava V, Patankar A, Bose M. Particle velocity distribution in a flow of gas-solid mixture through a horizontal channel. Powder Technology. 2016;298:119-129. DOI: 10.1016/j. powtec.2016.04.049 